\title{
Immunization with a Plasmodium Falciparum Merozoite Surface Antigen Induces a Partial Immunity in Monkeys
}

\author{
L. H. Perrin, B. Merkli, M. S. Gabra, J. W. Stocker, C. Chizzolini, and R. Richle \\ Geneva Blood Center and Department of Medicine, Geneva University Hospital, 1211 Geneva 4, Switzerland; \\ and Hoffmann-La Roche, Inc., Pharmaceutical Research Division, 4002 Basel, Switzerland
}

\begin{abstract}
Saimiri monkeys immunized with a Plasmodium falciparum merozoite polypeptide of $41 \mathrm{kD}$ mol wt are resistant to a blood challenge infection that induces a fulminant infection in control monkeys. The sera of the immunized monkeys reacted, as shown by the indirect immunofluorescence technique, with the apical part of the merozoites from five isolates or clones of $P$. falciparum. Whether the immunogen was dissolved in nonionic detergent (NP-40) or in sodium dodecyl sulfate (SDS) had a marked influence on the level of protection in immunized monkeys. Thus, monkeys immunized with the antigen solubilized in a nonionic detergent developed much lower parasitemia than monkeys immunized with denatured antigen (antigen eluted from SDS polyacrylamide gel electrophoresis).
\end{abstract}

\section{Introduction}

Passive injection of human antimalarial antibodies inhibits the proliferation of asexual blood stages of Plasmodium falciparum in vivo (1). These antibodies seem to act against merozoites (2), which are the invasive forms of the parasite during the asexual cycle.

Several malarial antigens including a polypeptide of $41 \mathrm{kD}$ have been identified at the merozoite surface by sodium dodecyl sulfate polyacrylamide gel electrophoresis (SDS-PAGE) ${ }^{1}$ analysis and autoradiography of surface labeled purified merozoites $(3,4)$. This $41-\mathrm{kD}$ polypeptide may be identical to a polypeptide of similar molecular weight immunoprecipitated by monoclonal antibodies (5). These monoclonal antibodies present two interesting features: first, as shown by the indirect fluorescence technique, they react with two small spots located at the apical part of the merozoite's surface (probably the rhoptries) as recently confirmed by immunoelectromicroscopy (Aikawa, M., and L. H. Perrin, unpublished data), and secondly, they inhibit in vitro the growth of $P$. falciparum asexual blood stages (5).

Address reprint requests to Dr. Perrin, Geneva Blood Center, Cantonal University Hospital, 1211 Geneva 4, Switzerland.

Received for publication 25 October 1984 and in revised form 28 January 1985

1. Abbreviations used in this paper: ELISA, enzyme-linked immunosorbent assay; $\mathrm{Hb}$, hybridoma; IFA, indirect immunofluorescence; NP40, Nonidet P-40; SDS-PAGE, sodium dodecyl sulfate polyacrylamide gel electrophoresis.

J. Clin. Invest.

(c) The American Society for Clinical Investigation, Inc.

0021-9738/85/05/1718/04 \$1.00

Volume 75, May 1985, 1718-1721
The aim of this study was to purify the $41-\mathrm{kD}$ merozoite surface component, to immunize susceptible monkeys, and to evaluate their resistance to a blood induced challenge infection.

\section{Methods}

Preparation of immunoabsorbent. $50 \mathrm{ml}$ of ascitic fluid induced by injection into Balb/c mice of hybridomas $(\mathrm{Hb})$ secreting monoclonal antibodies against the $41-\mathrm{kD}$ polypeptide $(\mathrm{Hb} 28 \mathrm{cll})$ and against the 41-kD polypeptides and the $82-\mathrm{kD}$ polypeptides $(\mathrm{Hb} 31 \mathrm{cl} 3$ and $\mathrm{Hb}$ $50 \mathrm{cl}$ ) were pooled $(5,6) .200 \mathrm{mg}$ of Ig purified by $50 \%$ ammonium sulfate precipitation, were coupled to $10 \mathrm{ml}$ of cyanogen bromideactivated Sepharose 4B according to the manufacturer's recommendations (Pharmacia Fine Chemicals, Piscataway, NJ).

P. falciparum cultures. Asynchronous in vitro cultures of five $P$. falciparum isolates; SGE2 from Zaire, Palo-Alto, FCR3 clone A2, FCC2 (China), and M23 (Honduras) were grown as previously described (7). SGE2 and Palo-Alto cultures were labeled with $100 \mu \mathrm{Ci} / \mathrm{ml}$ of $\mathrm{L}\left[{ }^{35}\right.$ S]methionine (Amersham Corp., Arlington Heights, IL) for $6 \mathrm{~h}$ and the pelleted labeled cells were extracted in ice in $10 \mathrm{vol}$ of lysis buffer $(5 \mathrm{mM}$ Tris- $\mathrm{HCl}, 50 \mathrm{mM} \mathrm{NaCl}, 5 \mathrm{mM}$ EDTA, $1 \%$ Nonidet P-40 (NP-40), $2 \mathrm{mM}$ phenylmethylsulfonylfluoride, $\mathrm{pH}$ 7.2) (6). The insoluble material was removed by centrifugation at $60,000 \mathrm{~g}$ for 20 $\min$ at $4^{\circ} \mathrm{C}$ and the extract was kept at $-75^{\circ} \mathrm{C}$.

Eight series of 40 cultures of the SGE2 isolate, grown in $100-\mathrm{mm}$ diam petri dishes (Falcon Labware, Div. of Becton-Dickinson \& Co., Oxnard, CA), were used as starting material for purification of the 41kD polypeptide (7). Schizonts and merozoites were purified by differential centrifugation and the pellet was extracted with 7 vol of lysis buffer (7). The lysate was centrifuged at $30,000 \mathrm{~g}$ for $20 \mathrm{~min}$ at $4^{\circ} \mathrm{C}$ and the supernatant $(120 \mathrm{ml}$ total) was used for subsequent purification.

Purification of the $41-k D$ polypeptide. $40 \mathrm{ml}$ of schizont and merozoite extract supplemented with $2 \times 10^{8} \mathrm{cpm}$ of methionine labeled SGE2 extract used as tracer, were mixed overnight at $4^{\circ} \mathrm{C}$ with $20 \mathrm{ml}$ of immunoabsorbent. The mixture was poured into a $30-\mathrm{ml}$ column, washed with $120 \mathrm{ml}$ of lysis buffer containing $1 \% \mathrm{NP}-40$, and then washed with $60 \mathrm{ml}$ of lysis buffer containing $0.05 \%$ NP-40. Polypeptides were eluted at $4^{\circ} \mathrm{C}$ with $0.1 \mathrm{M}$ glycine $\mathrm{HCl}, \mathrm{pH} \mathrm{3}$, supplemented with $0.05 \%$ NP-40. 4-ml fractions were collected and immediately neutralized by the addition of $0.5 \mathrm{M}$ Tris- $\mathrm{HCl}, \mathrm{pH} 9.5$. Presence of the 41-kD polypeptide in the eluted fractions was monitored by analysis of subsamples on SDS-PAGE stained with Coomassie blue and autoradiographed $(7,8)$. Fractions containing the antigen were pooled, dialyzed against water overnight, lyophilized, and reconstituted in a volume of $3 \mathrm{ml}$ (procedure repeated three times). $5 \mathrm{ml}$ of this preparation containing $170 \mu \mathrm{g} / \mathrm{ml}$ of protein as measured by protein assay (Bio-Rad Laboratories, Richmond, CA) were applied on 3-mm thick $8 \%$ SDS-PAGE (procedure repeated five times). The $41-\mathrm{kD}$ band was identified on small gel strips, stained with Coomassie blue, cut with a razor blade in small pieces, and electroeluted in dialysis bags (9). The electroeluted preparation of $4 \mathrm{ml}$ containing $180 \mu \mathrm{g} / \mathrm{ml}$ of protein was called "SDS antigen," whereas the fraction eluted from the immunoabsorbent was called "NP-40 antigen."

Immunization schedule and challenge. Three groups of four Saimiri monkeys of Guyana origin, bred in the animal facilities of HoffmannLa Roche Inc. in Basel, Switzerland, were immunized. A control group of four monkeys was injected subcutaneously three times in four 
different sites, the first time with $0.5 \mathrm{ml}$ saline mixed with Freund's complete adjuvant, and the second and third times with $0.5 \mathrm{ml}$ saline mixed with Freund's incomplete adjuvant 16 and $30 \mathrm{~d}$ after the first immunization. The second and third groups of animals were immunized according to the same protocol with $40 \mu \mathrm{g}$ of either the NP-40 or SDS 41-kD polypeptide mixed with adjuvants.

Challenge and monitoring of the antibody response. The 12 monkeys were challenged $3 \mathrm{wk}$ after the last immunization by an intravenous injection into the tail vein with $2.5 \times 10^{7}$ parasites provided by a splenectomized monkey infected $7 \mathrm{~d}$ previously with the Uganda Palo Alto FUP strain of $P$. falciparum. Parasitemia was checked at intervals on Giemsa stained blood smears. Sera collected at different times were tested for antimalarial antibody by indirect immunofluorescence (IFA) (10), enzyme-linked immunosorbent assay (ELISA) test (11), and immunoprecipitation. For the ELISA test, 96-well Linbro ELISA plates (Flow Laboratories Inc., McLean, VA) were coated overnight at $4^{\circ} \mathrm{C}$ with $100 \mu \mathrm{l}$ of a solution containing the $41-\mathrm{kD}$ polypeptide either solubilized in NP-40 or eluted from SDS-PAGE $(100 \mathrm{ng} / \mathrm{ml}$ of the 41 $\mathrm{kD}$ polypeptide, $1 \mu \mathrm{g} / \mathrm{ml}$ of radioimmunoassay grade bovine serum albumin [BSA] in $0.1 \mathrm{M}$ bicarbonate buffer, $\mathrm{pH}$ 9). BSA was obtained from Sigma Chemical Co., St. Louis, MO. The wells were saturated with $1 \% \mathrm{BSA}$ in phosphate-buffered saline (PBS), pH 7.4. Serial dilutions in PBS supplemented with 0.5\% BSA of the monkeys' sera were added to the wells and the plates were incubated for $2 \mathrm{~h}$ at $20^{\circ} \mathrm{C}$. The wells were washed five times with $0.5 \%$ BSA in PBS supplemented with $0.04 \%$ of Tween twenty (Siegfried, Zofingen, Switzerland). Peroxidase conjugated IgG fraction goat anti-monkey (heavy and light chain specific) at a dilution of $1 / 1,000$ was used as revealing antibody (Cappel Laboratories, Cochranville, PA).

For immunoprecipitation experiments, $4 \times 10^{5} \mathrm{cpm}$ of $\left[{ }^{35} \mathrm{~S}\right] \mathrm{me}-$ thionine labeled $P$. falciparum Palo Alto or SGE2 extracts were incubated with $5 \mu \mathrm{l}$ of the various monkey sera and immune complexes were precipitated by protein A (7). The immunoprecipitates were analyzed on $8 \%$ SDS-PAGE and autoradiography $(7,8)$.

\section{Results}

Blood smears of the cell pellet used as starting material showed more than $85 \%$ schizonts, $15 \%$ of normal erythrocytes and other asexual blood stages, free merozoites (not counted), and pigment (not counted). Most of the pigment was removed by centrifugation. $1,590 \mu \mathrm{g}$ of the $41-\mathrm{kD}$ polypeptide was recovered by affinity chromatography from $120 \mathrm{ml}$ of the schizont and merozoite extract. Analysis of the recovered fraction showed a thick band of $41 \mathrm{kD}$; the $82-\mathrm{kD}$ polypeptide weakly recognized by two of the monoclonal antibodies used for the preparation of the immunoabsorbent was not detectable on optimally loaded gel (Fig. $1 A$ ), but was found in the washed-through fractions using immunoprecipitation (data not shown). There was no detectable difference in purity between the NP-40 41kD preparation and the SDS $41-\mathrm{kD}$ preparation (Fig. $1 A$ ). Prechallenge sera of the monkeys immunized with both antigenic preparations reacted by IFA, on preparation of SGE2 parasites, diffusely with mature schizonts and with two small spots located on merozoites (pattern similar to the reactivity obtained using the monoclonal antibodies coupled to the immunoabsorbent). The end-point titer of prechallenge sera of monkeys immunized with the $41-\mathrm{kD}$ preparations varied between 1/160 and 1/640. There was no clear difference in antibody titers between the two groups of monkeys. Two sera from each group of immunized monkeys were also tested by
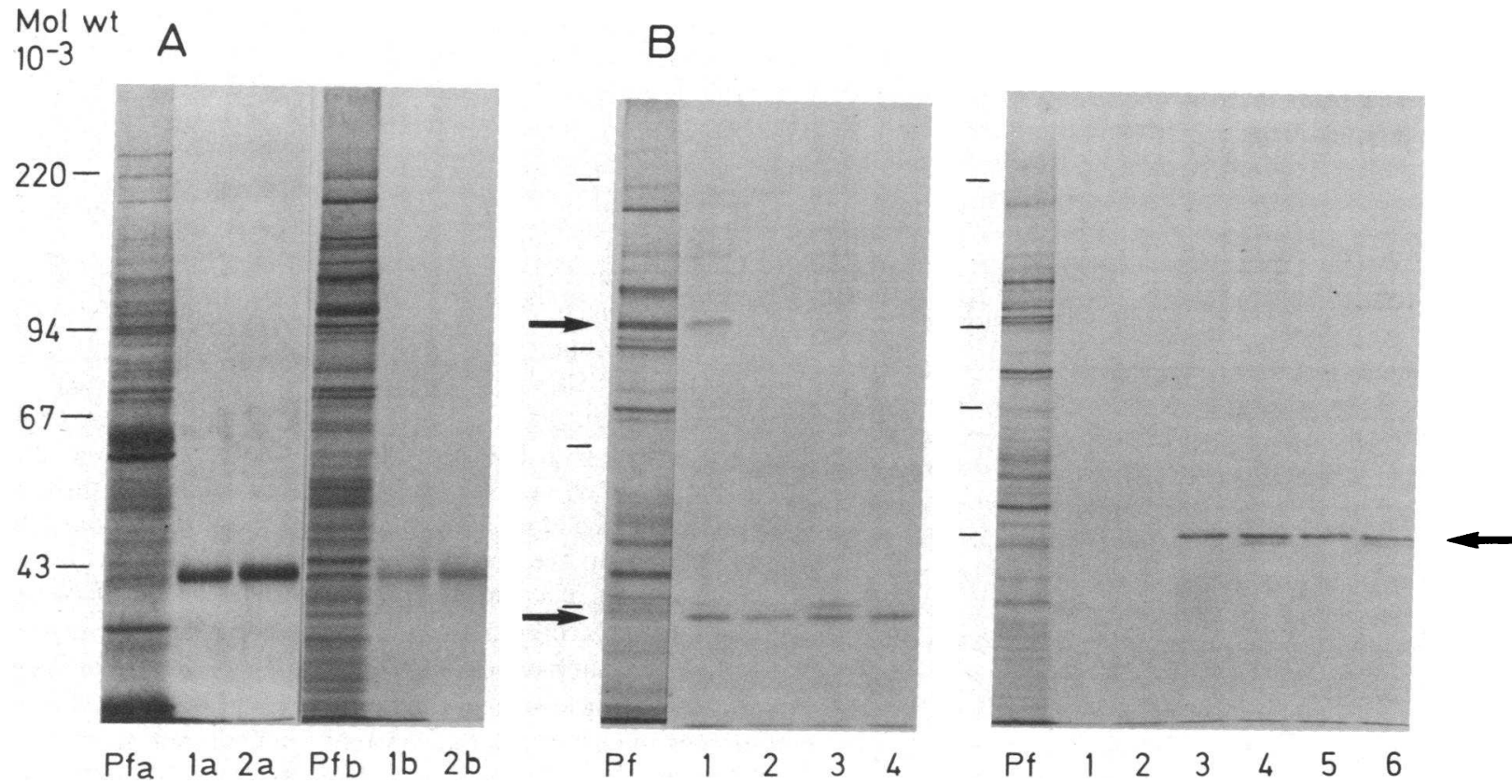

Figure 1. (A) Analysis by SDS-PAGE and autoradiography of $P$. falciparum schizont and merozoite extracts and 41-kD polypeptide preparations. Pfa, 1a, 2a; Coomassie blue stained gel: Pfb, 1b, 2b; autoradiography of the same gel. Pf, schizont and merozoite extract supplemented with $30,000 \mathrm{cpm}$ of $\left[{ }^{35}\right.$ S $]$ methionine labeled SGE2 extract; 1, material eluted from the immunoabsorbent (NP-40 $41 \mathrm{kD}$ polypeptide); 2, material eluted from SDS-PAGE (SDS $41 \mathrm{kD}$ polypeptide). $5 \mu \mathrm{g}$ of proteins were loaded on wells 2 and 3 .

(B) $\left[{ }^{35} S\right]$ methionine-labeled polypeptides immunoprecipitated by prechallenge sera of the four monkeys immunized with the SDS $41 \mathrm{kD}$ polypeptide (lanes 1-4, first part), of two monkeys of the control group (lanes 1 and 2, second part) and of the four monkeys immunized with the NP-40 $41 \mathrm{kD}$ polypeptide (lanes 3-6, second part). Pf, SGE2 extract labeled with $\left[{ }^{35} \mathrm{~S}\right]$ methionine, used as starting material for immunoprecipitation. Arrows indicate polypeptides of 105 and 41 kD. Reference molecular weights are indicated for each gel. 
IFA for their reactivity with five different isolates or clones of $P$. falciparum. The four sera tested at a dilution of $1 / 100 \mathrm{had}$ the same reactivity with parasites from the five preparations.

The antibody response of the two groups of immunized monkeys was determined more quantitatively using an ELISA assay. The results reported in Table I show that monkeys immunized with the 41-kD SDS antigen had very high titers against the SDS antigen but that both groups of monkeys had relatively similar titers against the NP-40 $41 \mathrm{kD}$ antigen.

The prechallenge sera of both groups of immunized monkeys precipitated a $\left[{ }^{35} \mathrm{~S}\right.$ ]methionine labeled polypeptide of 41 $\mathrm{kD}$; one serum precipitated both a $41-\mathrm{kD}$ polypeptide and a 105-kD polypeptide (Fig. 1 B). Similar results were obtained using $\left[{ }^{35} \mathrm{~S}\right]$ methionine-labeled extracts of SGE2 or Palo Alto as starting material.

After blood induced challenge infection, the four control monkeys developed very high parasitemia and were treated with quinine and Fansidar (Hoffmann-La Roche, Inc.) when their parasitemia reached $20 \%$ (Fig. 2). Monkeys immunized with the $41 \mathrm{kD}$. SDS antigen also had relatively high parasitemia whereas monkeys immunized with the NP-40 $41 \mathrm{kD}$ antigen had low peak parasitemia of $0.01 \%, 0.008 \%, 0.09 \%$, and $1.2 \%$. All but one of the monkeys immunized with the NP-40 41 $\mathrm{kD}$ antigen spontaneously recovered. This single immunized monkey was in poor general condition and required amputation of part of its tail because of extensive necrosis. Antimalarial treatment was administrated to this monkey $15 \mathrm{~d}$ after challenge (parasitemia, 1.2\%) to prevent further deterioration of its condition. Weekly monitoring of blood smears of all monkeys for 4 mo after challenge did not reveal recrudescent patent parasitemia except for the three untreated monkeys of the group immunized with NP-40 $41 \mathrm{kD}$. In these monkeys a very low grade parasitemia was observed between days 22 and 40 with peak parasitemia of $0.04 \%, 0.08 \%$, and $0.18 \%$. None of the monkeys suffered from late complications in relation to the experiments described here.

Table I. Antimalarial Antibody Titers

\begin{tabular}{lllr}
\hline & & \multicolumn{2}{c}{ Antigens used for immunization } \\
\cline { 3 - 4 } $\begin{array}{l}\text { Antigen used for } \\
\text { coating }\end{array}$ & Monkeys & $41 \mathrm{kD} \mathrm{NP}-40$ & $41 \mathrm{kD} \mathrm{SDS}$ \\
\hline $41 \mathrm{kD} \mathrm{SDS}$ & 1 & 9,000 & 160,000 \\
& 2 & 6,000 & 170,000 \\
& 3 & 8,500 & 200,000 \\
$41 \mathrm{kD} \mathrm{NP-40}$ & 4 & 7,000 & 100,000 \\
& 1 & 2,000 & 1,800 \\
& 2 & 2,000 & 3,000 \\
& 3 & 1,000 & 800 \\
None & 4 & 1,500 & 1,800 \\
Control group & 1 & 40 & 40 \\
& 2 & 40 & 40 \\
\hline
\end{tabular}

Antimalarial antibody titers measured by an ELISA assay in prechallenge sera of three groups of monkeys immunized with NP-40 41 $\mathrm{kD}$, SDS $41 \mathrm{kD}$, and saline (control). These results are expressed as the dilution giving reading of 1.0 using a 492-nm filter. Plates coated with BSA followed by $1 / 40$ dilution of positive sera and antiimmunoglobulin gave a reading of 0.4 (background).

\section{Discussion}

These experiments indicate that Saimiri monkeys immunized with a 41-kD polypeptide, probably located in the rhoptries of $P$. falciparum merozoites, are at least partially resistant to a blood induced challenge infection that induced a fulminant infection in control monkeys. The results are similar to those obtained using whole merozoites and/or schizonts as immunogens $(11,12,13,14)$. The protective effect induced by immunization with the $41-\mathrm{kD}$ polypeptide is probably not dependent on strain specific determinant, on the basis of several observations. First, the immunized monkeys were challenged with an isolate Palo-Alto different from the isolate (SGE2) used for purification of the 41-kD polypeptide. Second, antigenic diversity has not been detected on the $41 \mathrm{kD}$ using monoclonal antibodies (6); and third, two sera of each group of immunized monkeys reacted with merozoites from all the isolates or clones of $P$. falciparum tested. These experiments and others in which partial protection was obtained using several soluble $P$. falciparum polypeptides (15) or individual schizont and merozoite specific polypeptides of 200 and 140 $\mathrm{kD}$, respectively (7), suggest that defined malarial antigens that are already being produced by DNA recombinant technology $(16,17)$ may have a practical use in the future.

The biological and physiological functions of the 41-kD polypeptide are not known. It has been suggested that binding to and penetration of merozoites into erythrocytes is a multistep process involving several components of both the erythrocyte membrane and the merozoite (18). It is likely that the $41-\mathrm{kD}$ polypeptide is involved in merozoite-erythrocyte interaction. This concept is supported by its localization and by the observation that monoclonal antibodies directed against this polypeptide inhibit the in vitro growth and multiplication of $P$. falciparum asexual blood stages (5).

The experiments reported here also suggest that the conformation of the $41-\mathrm{kD}$ polypeptide greatly affects the quality of the immune response. Immunization with the 41 SDS polypeptide induced very high levels of antibodies directed against the SDS antigen but comparatively low levels of antibodies against the native antigen. By comparing the effciency of parasite control achieved by the two groups of immunized monkeys, it seems that high levels of antibodies against the 41 SDS antigen are poorly effective. The group of monkeys immunized with the NP-40 $41 \mathrm{kD}$ antigen suffered from a relapse with low parasitemia but clearly achieved the best control of the malaria infection. However, the antibody titer of this group of monkeys against the NP-40 41-kD antigen is lower than in the group of monkeys immunized with the 41 SDS antigen. This observation may be related to a difference in the quality (avidity) of antibodies raised in the two groups of monkeys. Alternatively, it may be that the $41-\mathrm{kD}$ antigen is more efficient in its native form as inducer of cell mediated responses important for the control of malaria infection (19).

Finally, the possibility exists that trace contaminants that may be present in a higher concentration in the NP-40 41-kD preparation may alter the above interpretation of the results. In this respect, further investigations are needed to establish if a precursor processed product relationship exists between high molecular weight polypeptide(s) and the $41-\mathrm{kD}$ polypeptide (one of the monkey's sera precipitated a polypeptide of 105 $\mathrm{kD})$. In relation to this aspect, we have not detected any 

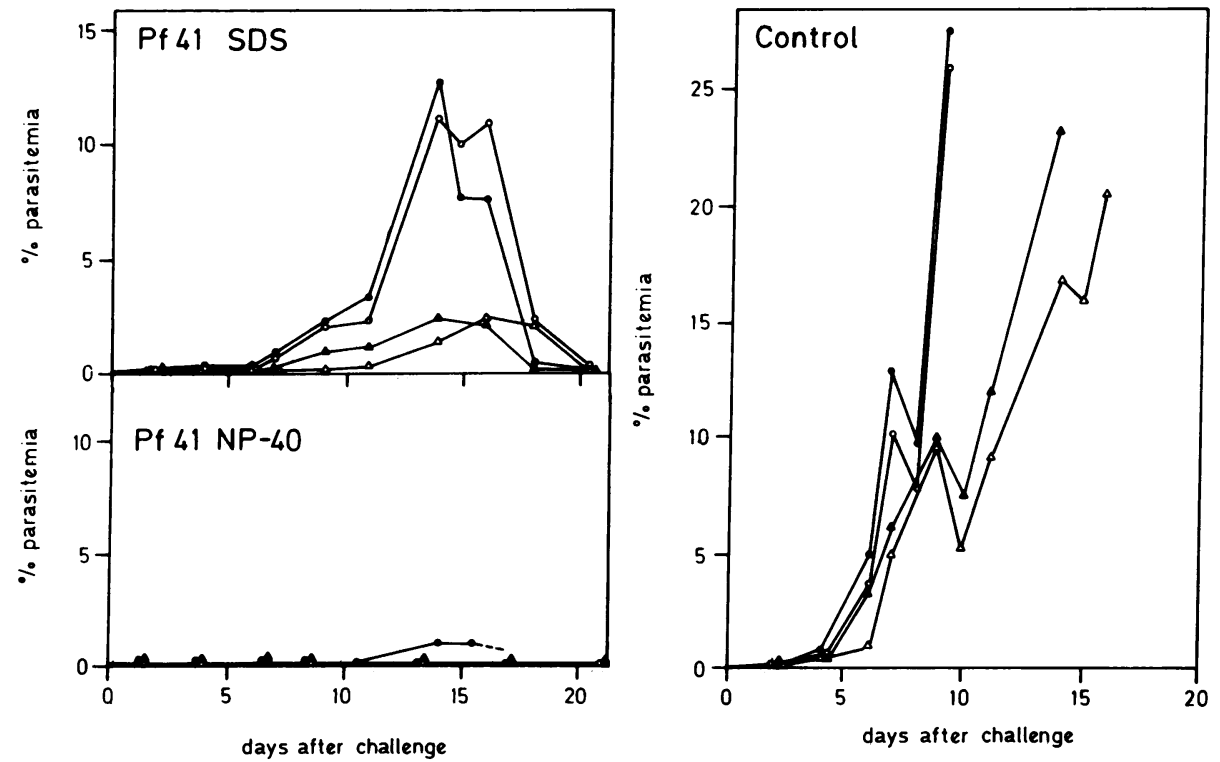

Figure 2. Course of parasitemia in three groups of four monkeys immunized with SDS $41 \mathrm{kD}$ (Pf $41 \mathrm{SDS})$, NP-40 $41 \mathrm{kD}$ (Pf $41 \mathrm{NP}-40$ ), and saline (control), respectively. structural analogy (7; and footnote 2) between the 41-kD polypeptide and two high molecular weight polypeptides of 140 and $200 \mathrm{kD}$, which have previously been shown to induce a protective immunity (7). Whether a cumulative effect can be obtained by using a mixture of the three polypeptides for immunization remainş to be clarified.

\section{Acknowledgments}

We thank Mrs. I. Callegari, B. Scherz, and E. Ramirez for their excellent technical help and Mrs. M. Devouge for help in preparing the manuscript.

This work was supported by the Swiss National Research Foundation, grant no. 3.862.0.83; the United Nations Development Program/ World Bank/World Health Organization Special Program for Research and Training in Tropical Diseases; and Hoffmann-La Roche, Inc., which provided the animals and the facilities to work with them.

\section{References}

1. Cohen, S., I. A. McGregor, and S. C. Carrington. 1961. Gammaglobulin and acquired immunity to human malaria. Nature (Lond.). 192:733-735.

2. Cohen, S., and I. A. McGregor. 1963. Gammaglobulin and acquired immunity to malaria. In Immunity to Protozoan. P. C. C. Garmham and I. Roitt, editors. Blackwell Scientific Publications Ltd, Oxford, England. 123-159.

3. Heidrich, H. G., Strych, W., and J. E. K. Mrema. 1983. Identification of surface and internal antigens from spontaneously released Plasmodium falciparum merozoites: radioiodination and metabolic labelling of merozoites. Z. Parasitenkd. 69:715-722.

4. Freeman, R. R., and A. A. Holder. 1983. Surface antigens of malaria merozoites. A high molecular weight precursor is processed to an $83.000 \mathrm{~mol}$. wt form expressed on the surface of Plasmodium falciparum merozoites. J. Exp. Med. 158:1647-1653.

5. Perrin, L. H., E. Ramirez, P. H. Lambert, and P. A. Miescher. 1981. Inhibition of $P$. falciparum growth in human erythrocytes by monoclonal antibodies. Nature (Lond.). 289:301-303.

6. Perrin, L. H., and R. Dayal. 1982. Immunity to asexual

2. Each of the three purified and ${ }^{35} \mathrm{~S}$-methionine labeled polypeptides has been digested with trypsin and analyzed as described in reference 7. There was no analogy between the peptide profiles of each of the three peptides (Smart, J., and L. Perrin, unpublished data). erythrocytic stages of Plasmodium falciparum: role of defined antigens in the humoral immune response. Immunol. Rev. 61:245-269.

7. Perrin, L. H., B. Merkli, M. Loche, C. Chizzolini, J. Smart, and R. Richle. 1984. Antimalarial immunity in Saimiri monkeys: immunization with surface components of asexual blood stages. J. Exp. Med. 160:441-451.

8. Laemmli, U. K. 1970. Cleavage of structural proteins during their assembly of the head of bacteriophage T4. Nature (Lond.). 227: 680-685.

9. Allet, B., K. J. Katagiri, and R. F. Gesteland. 1973. Characterization of polypeptides made in vitro from bacteriophages Lambda DNA. J. Mol. Biol. 78:589-592.

10. O'Neil, P., and G. D. Johnson. 1970. Multispot immunofluorescence: a simple method of processing large number of tests. J. Clin. Pathol. (Lond.). 23:185-192.

11. Engwall, E., and P. Perlmann. 1971. Enzyme-linked immunoabsorbent assay (ELISA): quantitative assay of immunoglobulin. Immunochemistry. 8:871-879.

12. Siddiqui, W. A. 1977. An effective immunization of experimental monkeys against malaria parasite, Plasmodium falciparum. Science (Wash. DC). 197:388-390.

13. Mitchell, G. H., G. A. Butcher, W. H. G. Richards, and S. Cohen. 1977. Merozoite vaccination of Douroucouli monkeys against falciparum malaria. Lancet. I:1335-1338.

14. Trager, W., H. N. Lanners, H. A. Stanley, and S. G. Langreth. 1983. Immunization of owl monkey to Plasmodium falciparum with merozoites from cultures of a knobless clone. Parasite Immunol. (Oxf.). 5:225-231.

15. Dubois, P., J. P. Dedet, T. Fandeur, C. Roussilhon, M. Jendoubi, S. Pauillac, O. Mercereau-Pujalon, and L. Pereira da Silva. 1984. Protective immunization of the Squirel monkey against asexual blood stages of Plasmodium falciparum by use of parasite protein fractions. Proc. Natl. Acad. Sci. USA. 81:229-234.

16. Kemp, D. J., L. C. Ross, A. F. Cowman, R. B. Saint, G. V. Brown, and R. F. Anders. 1983. Expression of Plasmodium falciparum blood-stage antigens in Escherichia coli: detection with antibodies from immune humans. Proc. Natl. Acad. Sci. USA. 80:3787-3791.

17. McGarvey, M. J., E. Sheybani, M. P. Loche, L. Perrin, and B. Mach. 1984. Identification and expression in Escherichia coli of merozoite stage-specific genes of the human malarial parasite Plasmodium falciparum. Proc. Natl. Acad. Sci. USA. 81:3690-3694.

18. Pasvol, G., M. Jungery, D. J. Weatherall, S. F. Parsons, D. J. Anstee, and M. J. A. Tanner. 1982. Glycoprotein as a possible receptor for $P$. falciparum. Lancet. II:947-950.

19. Allison, A. C. 1984. Cellular immunity to malaria and Babesia: a personal viewpoint. Contemp. Top. Immunobiol. 12:463-490. 